Nova Southeastern University

Florida

NOVA SOUTHEASTERN

UNIVERSTYY

NSUWorks

Marine \& Environmental Sciences Faculty Articles Department of Marine and Environmental Sciences

$11-21-2014$

\title{
Comment on "Chemically Mediated Behavior of Recruiting Corals and Fishes: A Tipping Point That May Limit Reef Recovery"
}

\author{
Andrew H. Baird \\ James Cook University - Townsville, Australia \\ Vivian R. Cumbo \\ James Cook University - Townsville, Australia \\ Joana Figueiredo \\ Nova Southeastern University, $<<$ span class="elink">jfigueiredo@nova.edu \\ Saki Harii \\ University of the Ryukyus - Japan \\ Tom Hata \\ Stanford University \\ See next page for additional authors
}

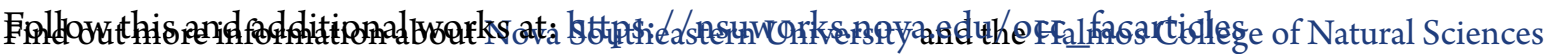

Partofragrepharine Biology Commons, and the Oceanography and Atmospheric Sciences and Meteorology Commons

\section{NSUWorks Citation}

Andrew H. Baird, Vivian R. Cumbo, Joana Figueiredo, Saki Harii, Tom Hata, and Joshua S. Madin. 2014. Comment on "Chemically Mediated Behavior of Recruiting Corals and Fishes: A Tipping Point That May Limit Reef Recovery”.PeerJ , (e628v1) : 1 -7.

https://nsuworks.nova.edu/occ_facarticles/557.

This Article is brought to you for free and open access by the Department of Marine and Environmental Sciences at NSUWorks. It has been accepted for inclusion in Marine \& Environmental Sciences Faculty Articles by an authorized administrator of NSUWorks. For more information, please contact nsuworks@nova.edu. 
Authors

Joshua S. Madin

Macquarie University - Sydney, Australia 
1 Comment on "Chemically mediated behavior of recruiting corals and fishes: A tipping

2 point that may limit reef recovery"

3

$4 \quad$ Baird $\mathrm{AH}^{1^{*}}$, Cumbo $\mathrm{VR}^{1}$, Figueiredo $\mathrm{J}^{2}$, Harii $\mathrm{S}^{3}$, Hata $\mathrm{T}^{4}$, Madin $\mathrm{JS}^{5}$

5

$6{ }^{1}$ ARC Centre of Excellence for Coral Reef Studies, James Cook University, Townsville,

7 Queensland, 4811, Australia

$8{ }^{2}$ Oceanographic Center, Nova Southeastern University, 8000 N Ocean Drive, Dania Beach,

9 FL 33004, USA

$10{ }^{3}$ Sesoko Tropical Biosphere Marine Station, University of the Ryukyus, Okinawa, Japan

$11 \quad{ }^{4}$ Hopkins Marine Station, Stanford University, Pacific Grove, CA 93950, USA

$12{ }^{5}$ Department of Biological Sciences, Macquarie University, NSW 2109, Australia

*corresponding author andrew.baird@jcu.edu.au

\section{Abstract}

Dixson et al. ${ }^{1}$ report that coral larvae navigate towards chemical cues associated with healthy reefs and avoid cues from degraded reefs. However, the swimming capabilities of coral larvae and well-established patterns of recruitment and reef hydrodynamics indicate that coral larvae will not be able to use these cues to recruit to healthy reefs.

\section{Main Text}

Dixson et al. (1) present a series of experiments suggesting that coral larvae can distinguish between chemical cues associated with healthy and degraded reefs, and subsequently imply that coral larvae will use these cues to navigate to healthy reefs. However, many of their results are contrary to our current understanding of coral larval swimming capabilities and 
well-established patterns of recruitment in the field. In addition, the flow structure in their flume is likely to be more dynamic than suggested, making choice experiments with coral larval difficult to interpret.

In a first set of flume experiments, larvae of three species of Acropora overwhelming preferred to spend time in water collected from areas of reefs protected from fishing when compared to water collected from areas lacking protection. However, coral larvae are very slow swimmers and based on previously published work are unlikely to be able to maintain their position in the flume for the 5 min duration of the experiment. The reported flow speed of $4.2 \mathrm{mms}^{-1}$ is greater than the mean of all average swimming speeds reported to date, even when larvae are assisted by gravity (i.e., swimming downwards; Fig. 1). The maximum horizontal swimming speed recorded for a coral larva is $3.45 \mathrm{mms}^{-1}$ (Table 1), which is well below the minimum speed required to maintain position in the flume, let alone navigate between the two water bodies. The remarkable consistency of larval behavior in the flume (Fig. 1A; Dixson et al.) is highly unusual and suggests that a physical rather than behavioral mechanism is operating. Indeed, the flow structure in their flume is likely to be much more complicated than they describe due to the presence of a barrier initially separating the two water sources and the barrier's abrupt end at the beginning of the test section. It is highly unlikely that visual inspection of a dye plume would sufficiently characterize flow conditions experienced by such small larvae in this flume. Well established techniques such as particle image velocimetry, laser-Doppler velocimetry or planar laser-induced fluorescence (2) should have been used to verify that flow biases do not exist at the scale relevant to coral larvae. The spatial pattern in the recruitment of corals to settlement tiles are also highly unusual for a reef system that has a high number of reefs in close proximity, such as Dixson et al. sites in Fiji. Their results imply a strong positive correlation between adult coral cover and recruitment to settlement tiles. Indeed, not a single recruit was found on tiles placed in 
51 the non-protected reef areas where coral cover was uniformly low. In contrast, in a two year study of 33 reefs spanning the length of Great Barrier Reef there was no correlation between adult abundance and coral recruitment to settlement tiles (3). Furthermore, only one of the 132 sites (4 sites per reef and 8 tiles per site) had no recruits (3). The lack of an effect of algal clearance on juvenile recruitment to the substratum is also anomalous. In contrast, artificial exclusion of herbivores reduces rates of coral juvenile recruitment 3-fold, presumably due to dramatic increases in abundance of seaweeds in herbivore exclusion plots (4). Even if coral larvae can distinguish between chemical cues associated with healthy and degraded reefs it is highly unlikely they will be able to use this information to navigate against ubiquitous tidal and other currents to preferred reefs for recruitment. Currents connecting reefs rarely fall below $100 \mathrm{mms}^{-1}$ (5), which is almost two-orders of magnitude greater than typical coral larval swimming speeds (Table 1; Fig. 1). All existing measures indicate that coral larvae are very slow swimmers and therefore will behave as passive particles relative to inter-reef hydrodynamic regimes (6). Perfuming degraded reefs, as suggested by Dixson et al., will not enhance recovery rather it will distract from the difficult task of reducing fishing effort and improving water quality. 


\section{References}

1. D. L. Dixson, D. Abrego, M. E. Hay, Chemically mediated behavior of recruiting corals and fishes: A tipping point that may limit reef recovery. Science 345, 892-897 (2014).

2. M. A. R. Koehl, Mini review: Hydrodynamics of larval settlement into fouling communities. Biofouling 23, 357-368 (2007).

3. T. P. Hughes, A. H. Baird, E. A. Dinsdale, N. A. Moltschaniwskyj, M. S. Pratchett, J. E. Tanner, B. L. Willis, Supply-side ecology works both ways: The link between benthic adults, fecundity, and larval recruits. Ecology 81, 2241-2249 (2000).

4. T. P. Hughes, M. J. Rodrigues, D. R. Bellwood, D. Ceccarelli, O. Hoegh-Guldberg, L. McCook, N. Moltschaniwskyj, M. S. Pratchett, R. S. Steneck, B. Willis, Phase shifts, herbivory, and the resilience of coral reefs to climate change. Curr. Biol. 17, 360-365 (2007).

5. R. Brinkman, E. Wolanski, E. Deleersnijder, F. McAllister, W. Skirving, Oceanic inflow from the Coral Sea into the Great Barrier Reef. Estuar. Coast Shelf Sci. 54, 655-668 (2002).

6. E. Wolanski, M. J. Kingsford, Oceanographic and behavioural assumptions in models of the fate of coral and coral reef fish larvae. J. Roy. Soc. Interface 11, 20140209 (2014).

7. N. Abe, Post-larval development of the coral Fungia actiniformis var. palawensis Doderlein. Palao Trop. Biol. Sta. Stud. 1, 73-93 (1937).

8. S. Harii, H. Kayanne, H. Takigawa, T. Hayashibara, M. Yamamoto, Larval survivorship, competency periods and settlement of two brooding corals, Heliopora coerulea and Pocillopora damicornis. Mar. Biol. 141, 39-46 (2002).

9. J. Harrigan, Ph. D., University of Hawaii, Honolulu (1972).

10. S. Motoda, Observation of Period of Extrusion of Planula of Goniastrea aspera (Verrill.). Kagaku Nanyo 1, 5-7 (1939).

11. D. F. Gleason, B. S. Danilowicz, C. J. Nolan, Reef waters stimulate substratum exploration in planulae from brooding Caribbean corals. Coral Reefs 28, 549-554 (2009).

12. K. Atoda, The larva and postlarval development of the reef-building corals IV Galaxea aspera (Quelch). J. Morphol. 89, 17-36 (1951).

13. K. Atoda, The larva and postlarval development of some reef-building corals I. Pocillopora damicornis cespitosa (Dana). Sci Rep Tohoku Uni 4th series (Biol) 18, 24-47 (1947).

14. K. Atoda, The larva and postlarval devlopment of the reef-building corals III. Acropora brueggemanni (Brook). J. Morphol 89, 1-16 (1951).

15. K. Atoda, The larva and post-larval development of some reef-building corals V. Seriatopora hystrix (Dana). Sci Rep Tohoku Uni 4th series (Biol) 19, 33-39 (1951). 
109 Table 1. Swimming speeds in $\mathrm{mms}^{-1}$ for hermatypic scleractinian coral larvae. $\mathrm{n}=$ number of

110 larvae; $\mathrm{SE}=$ standard error; $\mathrm{a}=$ mean calculated as average of maximum and minimum

111 value; $\mathrm{b}=$ mean calculated from larvae aged 2 to 7 days old.

112

\begin{tabular}{|c|c|c|c|c|c|c|c|c|}
\hline Species & $\begin{array}{l}\text { Swim } \\
\text { direction }\end{array}$ & Min & Max & Mean & $\mathrm{SE}$ & $\mathrm{n}$ & $\begin{array}{c}\text { Larvae } \\
\text { length } \\
(\mathrm{mm})\end{array}$ & Reference \\
\hline Heliogungia actinoformis & horizontal & 1.15 & 1.90 & 1.57 & 0.09 & 8 & 0.50 & (7) \\
\hline Pocillopora damicornis ${ }^{a}$ & horizontal & 1.67 & 1.88 & 1.78 & na & na & 1.00 & (8) \\
\hline Pocillopora damicornis ${ }^{b}$ & horizontal & 0.08 & 3.09 & 2.01 & 0.07 & 82 & 1.18 & (9) \\
\hline Coelastrea aspera $^{a}$ & horizontal & 2.00 & 3.45 & 2.73 & na & na & 0.47 & (10) \\
\hline Heliogungia actinoformis & up & 0.90 & 2.65 & 1.66 & 0.09 & 18 & 0.50 & $(7)$ \\
\hline Agaricia teunifolia & up & 1.04 & 3.16 & 2.10 & 0.20 & 28 & na & (11) \\
\hline Galaxea horrescens & up & 1.32 & 3.33 & 2.41 & 0.15 & 20 & 2.30 & (12) \\
\hline Pocillopora damicornis & up & 1.61 & 4.50 & 2.79 & 0.11 & 30 & 2.00 & (13) \\
\hline Porties asteroides & up & 1.26 & 4.34 & 2.80 & 0.20 & 59 & 0.75 & (11) \\
\hline Isopora bruggemanni & up & 1.10 & 4.55 & 2.86 & 0.24 & 20 & 2.50 & (14) \\
\hline Seriatopora hystrix & up & na & na & 3.33 & na & na & 1.50 & (15) \\
\hline Heliogungia actinoformis & down & 1.97 & 3.80 & 2.76 & 0.17 & 9 & 0.50 & $(7)$ \\
\hline Isopora bruggemanni & down & 2.56 & 5.56 & 3.55 & 0.18 & 20 & 2.50 & (14) \\
\hline Agaricia teunifolia & down & 2.01 & 5.19 & 3.60 & 0.30 & 28 & na & (11) \\
\hline Galaxea horrescens & down & 3.03 & 5.21 & 3.86 & 0.13 & 20 & 2.30 & (12) \\
\hline Porties asteroides & down & 2.76 & 5.84 & 4.30 & 0.30 & 59 & 0.75 & (11) \\
\hline Seriatopora hystrix & down & na & na & 4.44 & na & na & 1.50 & (15) \\
\hline Pocillopora damicornis & down & 3.68 & 6.49 & 4.79 & 0.13 & 30 & 2.00 & $(13)$ \\
\hline
\end{tabular}


115 Figure 1. Coral larvae are notoriously slow swimmers. The minimum swimming speed

116 required to hold position in the experimental flume used by Dixson et al. (4.2 $\mathrm{mms}^{-1}$, red star)

117 is more than twice the mean horizontal swimming speed of larvae in other studies. Mean

118 swimming speeds were taken from 14 studies representing over 450 speed measurements (for

119 references see Table 1. The raw data is available at coraltraits.org). An ANCOVA for log-

120 transformed speed data against larvae size and swimming direction found only a significant

121 effect of direction (after dropping size: $F_{2,15}=13.72, p<0.001$ ), where gravity-assisted

122 swimming (downward) was significantly faster than other swimming directions (letters a and

123 b denote significant differences at $a=0.05$, post-hoc Tukey’s test).

124

125 


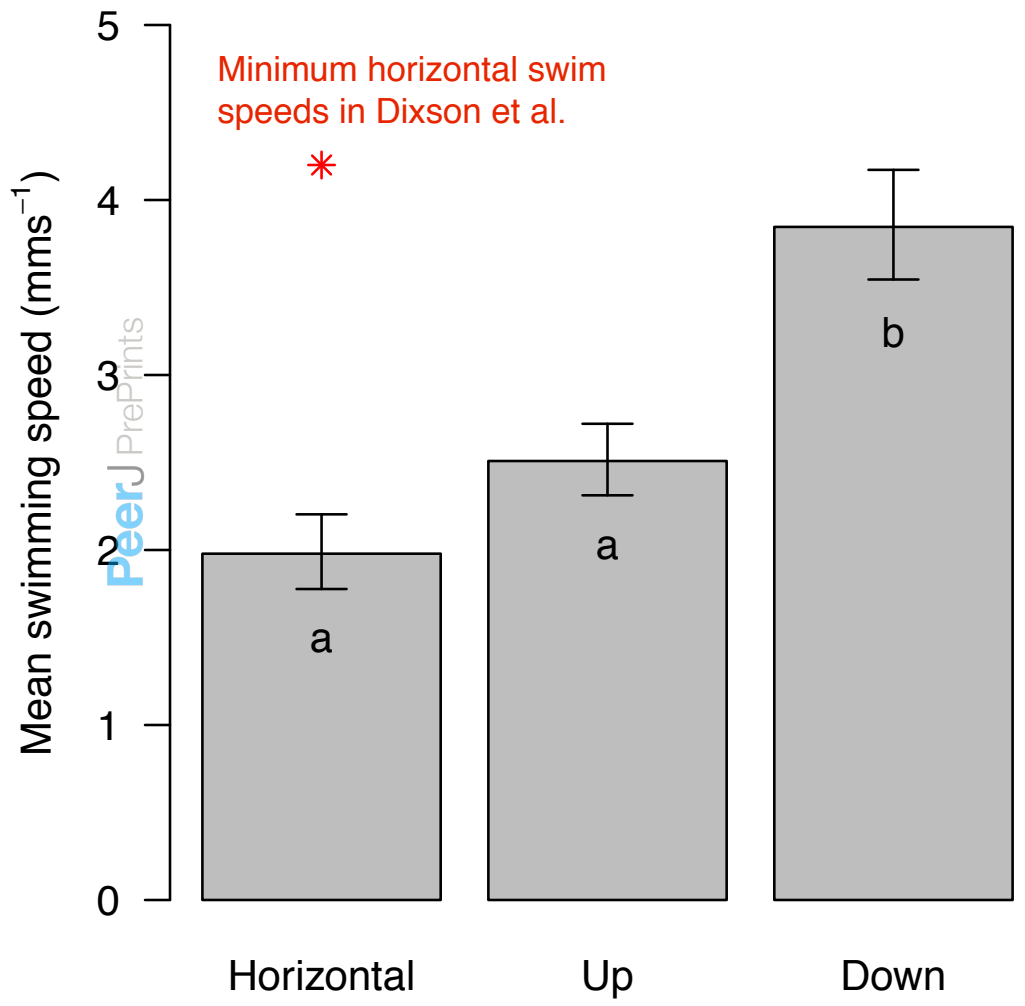

